\title{
Atomic Spectroscopy S \\ Clinimetallomics: Arsenic Speciation in Urine from Patients with Arsenism by HPLC-ICP-MS
}

\author{
Xiaohong Song, ${ }^{\mathrm{a}}$ Huiling Li, ${ }^{\mathrm{b}, *}$ Chao Ma, ${ }^{\mathrm{a}}$ Weiya Duan, ${ }^{\mathrm{a}}$ Youbao Sun, ${ }^{\mathrm{a}}$ Yueqi Li, ${ }^{\mathrm{a}}$ Taohong Huang, ${ }^{\mathrm{a}}$ \\ and Bo Zhou ${ }^{\text {b }}$ \\ a Shimadzu (China) Co., Ltd., Beijing 100020, P.R. China \\ b Department of Occupational Medicine and Clinical Toxicology, and Beijing Metallomics Facility, Beijing Chao-yang Hospital, Capital Medical University, \\ Beijing 100020, P.R. China
}

Received: March 18, 2021; Revised: April 30, 2021; Accepted: April 30, 2021; Available online: July 8, 2021.

DOI: 10.46770/AS.2021.103

ABSTRACT: Clinimetallomics is proposed as a branch of metallomics that focuses on the study of the metallome in clinical samples of urine, blood, and tissues. As the clinical diagnosis of arsenic poisoning is mainly based on the concentration of total arsenic in urine, the toxicity of arsenic varies greatly in different speciation. Analysis of arsenic speciation with excessive total arsenic in urine can provide a basis for precise treatment. It can also be used to understand the fate of arsenic in the body of patients with arsenic poisoning after treatment with sodium dimercaptopropane sulfonate. In this study, a HPLC-ICP-MS method was established for the determination of arsenic species in urine samples from patients diagnosed with arsenism. Use the established method to detect urine samples, which can be directly assayed after simple sample dilution with $20 \mathrm{mmol} / \mathrm{L}$ EDTA-2Na. With the concentration of arsenic speciation in the range of $1.0 \sim 100.0 \mathrm{ng} / \mathrm{mL}$, the linear correlation coefficient was higher than 0.99996 . The recoveries were between $91.1 \%$ and $111 \%$. The precision of the concentration was less than $5.00 \%$ and the detection limit was between $1.42 \mathrm{ng} / \mathrm{mL}$ and $1.86 \mathrm{ng} / \mathrm{mL}$. This method can be applied to arsenic speciation in the urine of healthy people, in patients treated for arsenic poisoning, and in patients diagnosed with arsenism.

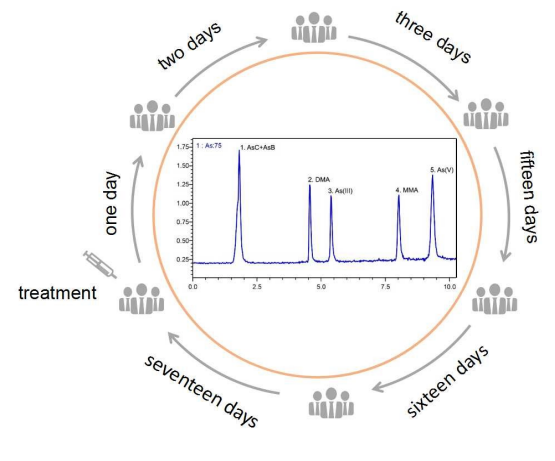

\section{INTRODUCTION}

There are more than 60 elements in the human body. The detection of clinical trace elements has been of wide concern. In modern clinical studies and research, the concentration of elements in biological samples is of great significance for the diagnosis and treatment of diseases. Clinimetallomics is proposed as a branch of metallomics, which focuses on the study of the metallome in clinical samples, such as urine, blood, and tissues.

Arsenic (As) can cause skin cancer, bladder cancer, lung cancer, nervous system disease or cardiovascular system diseases, especially due to long-term, low-dose exposure. Among the different arsenic compounds, arsenite [As(III)] and arsenate $[\mathrm{As}(\mathrm{V})]$ are the more toxic, methyl arsenate (MMA) and dimethyl arsenate (DMA) are less toxic, and arsenic betaine (AsB), arsenocholine (AsC) and arsenose are basically non-toxic. ${ }^{1}$
The metabolism and transformation in the organism make arsenic become complex. Many studies have shown that after arsenic exposure, inorganic arsenic mainly undergoes a methylation process in vivo. The donor of methyl in vivo is provided with inorganic arsenic under the action of methyltransferase to produce the methylation metabolites of MMA and DMA. ${ }^{2,3}$ DMA accounts for $60 \sim 80 \%$, MMA for $10 \sim 20 \%$, and the remaining $10 \sim 30 \%$ are directly excreted as inorganic arsenic. ${ }^{4}$ Generally, speciation of As in human urine has been reported by using HPLC-ICP-MS, IC-ICP-MS or complementary chromatography combined with hydride generation ICP-MS. ${ }^{5-13}$ There were few studies on the speciation determination of arsenic in human blood. The research in this area only includes animal experiments with plasma and red blood cells of rats and in vitro experiments with human blood samples. ${ }^{14,15}$ 
Urine is an easily available sample and urinary arsenic is an ideal biomarker to establish current arsenic exposure. In recent years, the speciation of urinary arsenic has been used to study occupational arsenism. ${ }^{16,17}$ Arsenic compounds can also be used as a therapeutic drug. Some studies have found that arsenic trioxide can effectively treat acute myeloid leukemia (APL). However, there are few reports on the speciation analysis of urinary arsenic in clinical patients receiving arsenic treatment. ${ }^{18}$

In this work, a reliable method based on HPLC-ICP-MS was developed to evaluate the level of As species in urine samples from patients diagnosed with arsenism. Urine samples can be directly analyzed by the proposed method after simple sample dilution.

\section{EXPERIMENTAL}

Instruments. LC-20Ai Liquid Chromatography system (Shimadzu, Japan), ICP-MS-2030 Inductively Coupled Plasma Mass Spectrometer (Shimadzu, Japan), AY-120 electronic balance (Shimadzu, Japan), Advantage A10 ultrapure water analyzer (Milli-q, Switzerland).

Reagents. Arsenic Choline (AsC) reference material (As: $28.0 \pm 1.1 \mu \mathrm{g} / \mathrm{g}$ ), Arsenic Betaine (AsB) reference material $(38.8 \pm 1.1 \mu \mathrm{g} / \mathrm{g})$, Arsenate (As (V)) reference material (17.5 \pm 0.4 $\mu \mathrm{g} / \mathrm{g}$ ), Arsenite (As(III)) reference material $(75.7 \pm 1.2 \mu \mathrm{g} / \mathrm{g})$, Dimethyl Arsenic (DMA) reference material (52.9 $\pm 1.8 \mu \mathrm{g} / \mathrm{g}$ ), and Methyl Arsenic (MMA) $(25.1 \pm 0.8 \mu \mathrm{g} / \mathrm{g})$ were purchased from the National Institute of Metrology, P.R. China. Sodium Ethylenediaminetetraacetate (EDTA-2Na), Triton, and Ammonium Carbonate are analytically pure and were purchased from Sinopharm Chemical Reagent Co., Ltd. Methanol is chromatographic pure and was purchased from Merck Co., Ltd.

Chromatographic Conditions. The chromatographic conditions were as follows, chromatographic column: Dionex IonPac ${ }^{\mathrm{TM}}$ AS19 (4 x $250 \mathrm{~mm}, 7.5 \mu \mathrm{m})$; mobile phase: A phase-50 mmol/L ammonium carbonate solution ( $\mathrm{pH}=9$ ), B phase-Water; Flow Rate: $1.2 \mathrm{~mL} / \mathrm{min}$; column temperature: $30^{\circ} \mathrm{C}$; injection volume: $20 \mu \mathrm{L}$; elution procedure: gradient elution. Gradient elution parameters were shown as Table 1.

Standard Curve. A proper amount of the reference stock solution was put into volumetric flask and $20 \mathrm{mmol} / \mathrm{L}$ EDTA-2Na (containing $0.1 \%$ Triton) solution added to make a mixed solution with a series of concentrations of $1.0 \mathrm{ng}, 4.0 \mathrm{ng}, 10.0 \mathrm{ng}, 20.0 \mathrm{ng}$, $50.0 \mathrm{ng}$ and $100.0 \mathrm{ng}$ (all based on arsenic) per $1 \mathrm{~mL}$, then shaken well and set aside. The standard curve was drawn with the peak area (y) as the ordinate and the arsenic concentration (x) as the abscissa. The Lab solutions ICP-MS version 1.02 workstation was used for data acquisition and analysis, and an external standard method was used for quantitative analysis.

Sample preparation. The urine samples were diluted 20 times with $20 \mathrm{mmol} / \mathrm{L}$ EDTA-2Na (containing $0.1 \%$ Triton).
Table 1. Gradient Elution Parameters

\begin{tabular}{ccc}
\hline Time (min) & A Phase (\%) & B Phase (\%) \\
\hline 0 & 0 & 100 \\
5 & 100 & 0 \\
9 & 100 & 0 \\
10 & 0 & 100 \\
25 & 0 & 100 \\
\hline
\end{tabular}

\section{RESULTS AND DISCUSSION}

Optimization of Elution Conditions of Arsenic Acid (As(V). In this work, a gradient separation method with $50 \mathrm{mmol} / \mathrm{L}$ ammonium carbonate aqueous solution $(\mathrm{pH}=9)$ and pure water as the mobile phase was attempted. The gradient elution parameters were as follows, time: 0-15 min; A phase (\%): 0-100; $\mathrm{B}$ phase (\%): 0-100. The chromatogram results were shown in Fig. 1. The peak shapes of DMA, As (III), and MMA were obtained under above conditions. However, when the ratio of buffer to water was small, the peak width of As (V) was wide, which affects the detection sensitivity of $\operatorname{As}(\mathrm{V})$. When the chromatographic conditions were changed into those shown in Table 1, the peak of As(V) was narrowed (as shown in Fig. 2) and the sensitivity was improved. Because a steep gradient significantly could reduce the peak width of the compound arsenate, $(\mathrm{As}(\mathrm{V}))$, thus the detection sensitivity of the compound was improved.

Effect of the column equilibrium time. Column equilibrium is a necessary step in gradient elution. The retention time and peak shape of four target compounds were studied after column equilibration for $5 \mathrm{~min}, 10 \mathrm{~min}$, and $15 \mathrm{~min}$. As shown in Fig. S1,
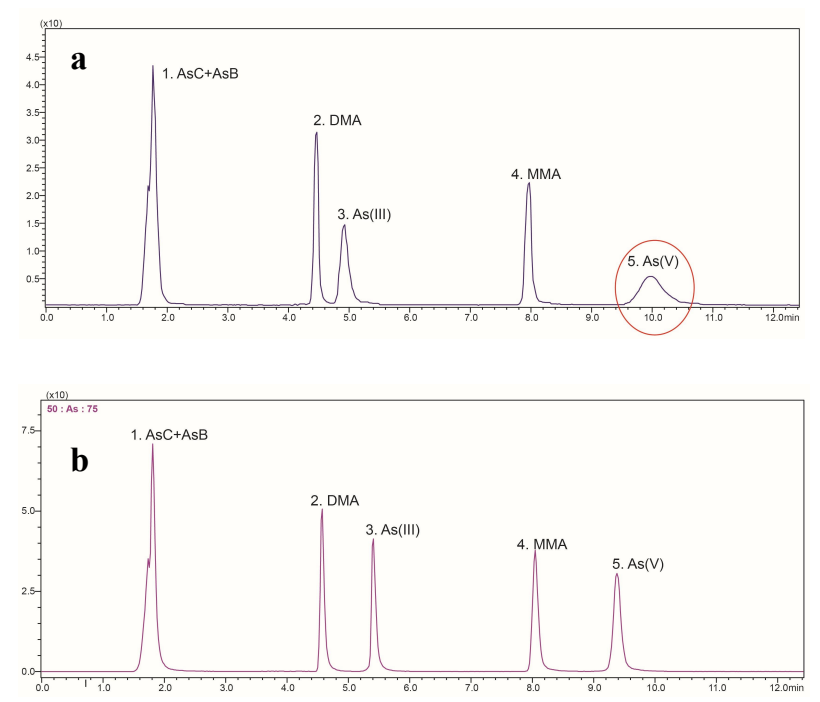

Fig. 1 The chromatographic peaks for As species under different gradient elution parameters. a) time: 0-15 min; A phase (\%): 0-100; B phase (\%): 0100; b) list in Table 1. 
Table 2. The Analytical Performance for this Method

\begin{tabular}{llll}
\hline $\begin{array}{l}\text { Target } \\
\text { Object }\end{array}$ & $\begin{array}{c}\text { Instrument } \\
\text { detection limit } \\
(\mathbf{n g} / \mathbf{m L})\end{array}$ & $\begin{array}{l}\text { Method } \\
\text { detection limit } \\
(\mathbf{n g} / \mathbf{m L})\end{array}$ & $\begin{array}{c}\text { Linear Range } \\
(\mathbf{n g} / \mathbf{m L})\end{array}$ \\
\hline DMA & 0.07 & 1.42 & $1.0-100$ \\
As(III) & 0.09 & 1.70 & $1.0-100$ \\
MMA & 0.09 & 1.86 & $1.0-100$ \\
As(V) & 0.08 & 1.56 & $1.0-100$ \\
\hline
\end{tabular}

when the equilibrium time was $5 \mathrm{~min}$, the half peak width of As (III) was wide and there was an obvious tailing phenomenon, which leaded to the low detection sensitivity of As (III). After extending the column equilibrium time $(10 \mathrm{~min})$, the half peak width of As (III) becomes smaller and the tailing peak becomes a forward peak. Although the half peak width was small, the peak width and sensitivity still needed to be improved due to the stretching peak. After 15 min of equilibrium time, the peak shape and sensitivity of various forms of arsenic were better. Therefore, 15 min was chosen as the equilibrium time.

Investigation of specificity. The single standard solution and mixed standard solution of four forms of arsenic were used to investigate system interference. The resolutions of four compounds were achieved to ensure that false positive detection would not be caused in the actual sample analysis process. The chromatographic separation diagram is shown in Fig. 2. The resolution of four toxic species were greater than 1 , and there was no false positive detection.

Analytical performance. The detection limit was investigated under the condition that the injection volume was $20 \mu \mathrm{L}$. The signal-to-noise ratios of four arsenic species were investigated for the mixed standard solution with the concentration of 1.0 $\mathrm{ng} / \mathrm{mL}$, and the corresponding concentration of three times the signal-to-noise ratio $(3 \mathrm{~S} / \mathrm{N})$ peak height was taken as the detection limit. The detection limits of four arsenic species with a concentration of $1.0 \mathrm{ng} / \mathrm{mL}$ were shown in Table 2 . According to the peak area and the standard concentration, the standard concentration curve was established in the range of 1.0-100.0 $\mathrm{ng} / \mathrm{mL}$. The linear correlation coefficients of the four toxic forms of arsenic were greater than 0.99996. As listed in Table S1, the recoveries were from 91.1 to $111 \%$ with the concentration precisions (RSD) were less than $5.00 \%$.



Fig. 2 The typical chromatogram of arsenic species.
Table 3. Results of Urinary Arsenic in Patients with Arsenism (ng/mL)

\begin{tabular}{lllllll}
\hline Time & AsC+AsB & DMA & As(III) & MMA & As(V) & Sum species \\
The 1st day & N.D. & 1094 & 1340 & 814 & 270 & 3518 \\
The 2nd day & N.D. & 125 & 179 & 99.4 & 67.0 & 470 \\
The 3rd day & N.D. & 130 & 56.6 & 76.4 & 78.0 & 340 \\
The 15th day & N.D. & 8.36 & 7.30 & 13.5 & 8.38 & 38.0 \\
The 16th day & N.D. & N.D. & N.D. & 10.3 & 12.4 & 23.0 \\
The 17th day & N.D. & N.D. & N.D. & N.D. & 6.42 & 6.00 \\
\hline
\end{tabular}

Real samples analysis. The urine arsenic concentrations were detected in patients who received arsenic poisoning after realgar powder administration. The samples were diluted 20 times with $20 \mathrm{mmol} / \mathrm{L}$ EDTA-2Na (containing $0.1 \%$ Triton) and analyzed by HPLC-ICP-MS. The results of the random urine test showed that the concentration of arsenic in urine was $6.7 \mu \mathrm{g} / \mathrm{mL}$. After the poisoned patients were treated with sodium Dimercapto propane sulfonate to detoxify, the arsenic concentrations of the urine samples were determined to evaluate the curative effect. The results showed that $\mathrm{AsC}+\mathrm{AsB}$ were not detected in urine, the concentration of other forms of arsenic gradually decreased during the treatment. As(III) decreased significantly and cannot be detected after a 16-day detoxification treatment. On the 15 th day, the total arsenic was less than $0.1 \mu \mathrm{g} / \mathrm{mL}$, which was lower than the poisoning limit. In general, the brief metabolic process of arsenic in the body is as follows: $\mathrm{iAs}(\mathrm{III}) \rightarrow \mathrm{iAs}(\mathrm{V}) \rightarrow$ $\mathrm{MMA}(\mathrm{V}) \rightarrow \mathrm{MMA}(\mathrm{III}) \rightarrow \mathrm{DMA}(\mathrm{III}) \rightarrow \mathrm{DMA}(\mathrm{V}) \rightarrow$ urine excretion. The arsenic metabolism after realgar administration led to the concentration increase of DMA and MMA in the urine of the patients, and the concentration was significantly higher than the control group. ${ }^{19}$ After the detoxification treatment with sodium Dimercapto propane sulfonate, As(III)) was excreted from the body, and other forms of arsenic were gradually reduced. The detailed results are shown in Table 3.

\section{CONCLUSIONS}

An HPLC-ICP-MS method was developed for the determination of different arsenic forms in urine samples in patients with arsenism. Our results shows that the contents of DMA and MMA in the urine of patients taking realgar powder were higher than for healthy people. After the detoxification treatment with sodium mercaptopropanesulfonate, As(III) was excreted from the body, and other forms of arsenic were gradually reduced.

\section{ASSOCIATED CONTENT}

\section{Supporting Information}

The Supporting Information (Fig S1, Table S1) is available at www.at-spectrosc.com/as/home 


\section{AUTHOR INFORMATION}

\section{Corresponding Author}

*H. L. Li

Email address: 2584422151@qq.com

\section{Notes}

The authors declare no competing financial interest.

\section{ACKNOWLEDGMENTS}

The authors gratefully thank the research and development program of the Beijing Municipal Administration of Hospital (PX2016024) for the financial support of this work.

\section{REFERENCES}

1. P. F. Jin, X. J. Wu, D. Zou, Y. M. Kuang, X. Hu, W. Q. Jiang, and C. H. Sun. Spectrosc. Spect. Anal., 2011, 31, 816-819. https://doi.org/10.3964/j.issn.1000-0593(2011)03-0816-04

2. H. V. Aposhian, A. Arroyo, M. E. Cebrian, R. L. Del, K. M. Hurlbut, R. C. Dart, D. Gonzalez-Ramirez, H. Kreppel, H. Speisky, A. Smith, M. E. Gonsebatt, P. Ostrosky-Wegman, and M. M. Aposhian, J. Pharmacol. Exp. Ther, 1997, 282, 192-200.

3. H. V. Aposhian, Ann. Rev. Pharmacol. Toxicol., 1997, 37, 397-419. https://doi.org/10.1146/annurev.pharmtox.37.1.397

4. X. H. Wang and J. C. Bian, Foreign medicine (Medical Geography), 2005, 26, 101-105.

5. L. W. Chen, X. Lu, and X. C. Le, Anal. Chim. Acta., 2010, 675, 71-75. https://doi.org/10.1016/j.aca.2010.06.038

6. R. Xie, W. Johnson, S. Spayd, G. S. Hall, and B. Buckley, Anal. Chim. Acta., 2006, 578, 186-194. https://doi.org/10.1016/j.aca.2006.06.076
7. S. I. Miyashita, K. Kinoshita and T. Kaise, Anal. Sci., 2021, 37, 381-386. https://doi.org/10.2116/analsci.20N019

8. P. J. Wegwerth, S. A. Erdahl, M. L. Wermers, M. M. Hanley, S. J. Eckdahl, and P. J. Jannetto, J. Appl. Lab. Med., 2021, jfaa226. https://doi.org/10.1093/jalm/jfaa226

9. S. Tokalioglu, R. Clough, M. Foulkes, and P. Worsfold, Biol. Trace Elem. Res., 2020, 198, 332-338. https://doi.org/10.1007/s12011-020-02066-2

10. I. Sen, W. Zou, J. Alvaran, L. Nguyen, R. Gajek, and J. She, J. AOAC Int., 2015, 98, 517-523. https://doi.org/10.5740/jaoacint.14-103

11. K. A. Asante, T. Agusa, C. A. Biney, W. A. Agyekum, M. Bello, M. Otsuka, T. Itai, S. Takahashi, and S. Tanabe, Sci. Total. Environ., 2012, 424, 63-73. https://doi.org/10.1016/j.scitotenv.2012.02.072

12. A. Hata, K. Yamanaka, M. A. Habib, Y. Endo, N. Fujitani, and G. Endo, Environ. Health Prev. Med., 2012, 17, 235-245. https://doi.org/10.1007/s12199-011-0247-5

13. J. Morton and E. Leese, Anal. Bioanal. Chem., 2011, 399, 1781-1788. https://doi.org/10.1007/s00216-010-4180-z

14. B. Chen, X. Lu, S. Shen, L. L. Arnold, S. M. Cohen, and X.C.Le, Chem. Res. Toxicol., 2013, 26, 952-962. https://doi.org/10.1021/tx400123q

15. Y. Higashikawa, Y. Kazui, S. Suzuki, and O. Ohtsuru, J. Anal. Toxicol., 2008, 32, 344-348. https://doi.org/10.1093/jat/32.5.344

16. J. J. Zhong, S. G. Li, and K. G. Wu, Gansu Medical Journal, 2012, 31, 245-247. https://doi.org/10.15975/j.cnki.gsyy.2012.04.026

17. L. Q. Su, Y. L. Jin, Y. B. Cheng, S. B. Lin, H. Z. Yan, L. Ding, and Y. Gu, J. Environ. Health, 2008, 25, 388-390. https://doi.org/10.16241/j.cnki.1001-5914.2008.05.018

18. Y. Fukai, M. Hirata, M. Ueno, N. Ichikawa, H. Kobayashi, H. Saitoh, T. Sakurai, K. Kinoshita, T. Kaise, and S. Ohta, Biol. Pharm. Bull., 2006, 29, 1022-1027. https://doi.org/10.1248/bpb.29.1022

19. Q. R. Liang, R. Qin, L. M. Qin, Z. M. Zhang, Z. D. Mai, and X. P. Li, Industrial Health and Occupational Diseases. 2015, 41, 263-268. https://doi.org/10.13692/j.cnki.gywsyzyb.2015.04.006 